\title{
A Framework for Exploring Blockchain Technology in Supply Chain Management
}

\author{
Abbas Batwa \\ Department of Industrial Management and Logistics, Faculty of Engineering (LTH), \\ Lund University, Sweden \\ E-mail: abbas.batwa@tlog.lth.se \\ Andreas Norrman \\ Department of Industrial Management and Logistics, Faculty of Engineering (LTH), \\ Lund University, Sweden \\ E-mail: andreas.norman@tlog.lth.se
}

\begin{abstract}
The purpose of the study is to identify and explore different applications of blockchain technology in supply chain management and suggest a framework for their analysis. The study addresses researchers' conflicting opinions regarding the hype of blockchain and clarifies which minor applications are hyped and which are currently more applicable. That helps supply chain practitioners appraise the different applications of blockchains before it is too late to revise a decision regarding their use. The framework was developed based on a systematic literature review of blockchain-related articles, and it was examined with semi-structured interviews with four companies that applied the technology. Findings from the study suggested that traceability and supply chain finance seemed to be the most applicable applications of blockchain technology in supply chain management. But, light was also shed on other applications such as: compliance with standards, supply chain integration and digitalization of the transactions. This study was restricted by the availability of applied cases, as blockchain remains an emerging technology. Therefore, this study cannot be considered a case research, but a literature review followed by a limited number of interviews. However, the study resulted in a conceptual framework that forms the basis for further exploratory studies with more empirical data.
\end{abstract}

Keywords: supply chain, blockchain, traceability, supply chain finance, compliance, digitalization, integration

\section{INTRODUCTION}

Blockchain technology (BCT) was introduced in 2008 as the concept behind the Bitcoin digital currency, first proposed by an anonymous programmer using the pseudonym Satoshi Nakamoto. Initially, Bitcoins struggled to get traction, and many questioned this new currency (Nakamoto, 2008). However, a boom occurred in 2013 when the value of one Bitcoin increased from 13.96 USD to 979.45 USD, meaning a price increase of $6900 \%$ in less than a year. Since then, researchers and industries have asked what makes this currency unique, and how the technology behind it can be harnessed (Iansiti and Lakhani, 2017). Some argue that BCT also provides unique features that will improve supply chain management (SCM; Iansiti and Lakhani, 2017; Loop, 2016; Yli-Huumo et al., 2016), but if and how remains to be proven. A first step would be to explore what BCT could really mean for SCM.
There are many explanations for BCT in the literature, but not one clear definition. To simplify how BCT works, one can imagine a chain of blocks containing information, as the name indicates. The complete blockchain works as a distributed ledger that is open to anyone. Each block contains three main elements: data, the hash of the block, and the hash of the previous block. The data depend on the type of the blockchain, and could be the sender, the receiver, and the amount transferred. The hash is a function that converts an input of letters and numbers into an encrypted output of a fixed length. To simplify, the hash of the block works as a unique fingerprint that defines the block and all its contents. When a change happens to the block or its data, the hash changes accordingly, and the block is no longer the same block. The third element is the hash of the previous block which is the feature of the blockchain that makes it secure against any change (Figure 1). If, for example, block 2 is changed, its hash changes; so, block 3 will not point to block 2 , and the following blocks will become invalid.

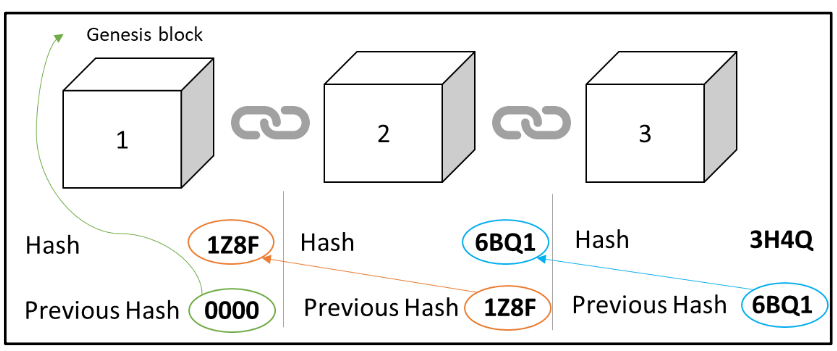

Figure 1 Simplification of the blockchain concept

The blockchain works as a network of nodes, meaning that each node has the exact same chain decentralized to its database. When there is a transaction, a new block is added to the chain, and each node then verifies the block to make sure that it has not been tampered with. Once the block is validated, each node adds the block to its blockchain. Thus, all the nodes in this network create consensus, which means they agree about which blocks are valid and which are not (Iansiti and Lakhani, 2017; Yli-Huumo et al., 2016).

The definition of SCM involves managing relationships and cross-functional business processes to ease the flows of products, finances, and information among the different parties in the supply chain (SC; Mentzer et al., 2001; Lambert and Enz, 2017). BCT intersects with SCM, as it can 
provide decentralized peer-to-peer transactions with no central party and with high transparency, immutability, and digitalization which enable one trusted and visible source of the information flow along the SC (Iansiti and Lakhani,
2017). The main defining attributes of BCT for Bitcoin are summarized in Table 1, but BCT could be adopted for other uses by altering some of the features (Yli-Huumo et al., 2016; Iansiti and Lakhani, 2017; Treiblmaier, 2018).

Table 1 Attributes that define BCT (Iansiti and Lakhani, 2017)

\begin{tabular}{|ll|}
\hline BCT Attributes & Explanation \\
\hline $\begin{array}{l}\text { Distributed database (open } \\
\text { Pccess) }\end{array}$ & $\begin{array}{l}\text { Each party in the blockchain has access to the entire database and its complete history with no } \\
\text { control for one party }\end{array}$ \\
$\begin{array}{l}\text { Communication occurs directly between nodes without a central node. Thus, every party can verify } \\
\text { the records of its transaction without any intermediary }\end{array}$ \\
$\begin{array}{l}\text { Irreversibility of records } \\
\text { Each node in the blockchain has a unique address, and users can choose either to remain } \\
\text { anonymous or to provide proof of their identity to others }\end{array}$ \\
$\begin{array}{l}\text { Many computational algorithms (proof of work) are deployed to ensure permanent records in the } \\
\text { database, chronologically ordered, and available to all others on the network }\end{array}$ \\
contracts)
\end{tabular}

Kshetri (2017) contended that BCT could make managing relationships in the SC network much easier, and much more efficient and safer. An example of the potential importance of BCT in SCM is the 2015 Escherichia coli (Ecoli) outbreak at Chipotle Mexican Grill outlets, which left 55 customers sick. Chipotle suffered a bad reputation due to negative news, restaurant shutdowns, and long investigations. Sales decreased dramatically, and the company's share price dropped by $42 \%$. The root causes lie partly in the reliance by Chipotle and other food companies on multiple suppliers to deliver their essential ingredients, with a severe lack of transparency and accountability across a complex SC. Chipotle was not able to monitor its suppliers in real time, as the process involved manual verification and massive record keeping that could be avoided using BCT (Casey and Wong, 2017).

Most cases mentioning BCT applications in SCM refer to the use of BCT in the SC traceability and data visibility context (Gurto and Johny, 2019). However, others argue that there could also be great potential for other applications of BCT in SCM (Van Hoek, 2019). For example, Maersk saved $15 \%$ of the shipping value that was dedicated to paperwork by applying BCT in a collaboration with IBM (Popper and Lohr, 2017). Maersk found that a single shipment of refrigerated goods from East Africa to Europe required stamps and approvals from up to 30 people, and more than 200 communications between them, such as those in customs, tax officials, and health authorities (Groenfeldt, 2017). Additional scattered applications of BCT in SCM can be found in cases or literature (Lee and Pilkington, 2017). For SCM researchers and practitioners to leverage this scattered knowledge base, and learn about this new phenomenon, there is a need to consolidate and analyze current cases for further exploration and evaluation.

The purpose of this study is: to identify and explore different applications of Blockchain Technology (BCT) in Supply Chaim Management (SCM) and suggest a framework for their analysis. Five research questions (RQs) were therefore developed:
RQ1: What are the drivers for using BCT in SCM?

$\boldsymbol{R Q 2 :}$ What are the BCT applications in SCM?

RQ3: What are the limitations and success factors of applying BCT in SCM?

RQ4: What is the impact of each BCT application on SC objectives?

RQ5: To what extent is BCT applicable in the SCM field?

This paper is organized as follows: The research methodology is described at the beginning, followed by findings from the literature review forming the basis for the initial framework. Then, the case studies' empirical findings are presented and analyzed. After that, the final framework is shown, and is followed by a concluding discussion that refers to the research questions. Finally, contributions, limitations, and suggestions for future research are given.

\section{METHODOLOGY}

In this study, a novel phenomenon (the application of BCT in SCM) is explored to develop a conceptual framework. There are descriptions of use cases available, partials of theory exist, but are scattered across many disciplines such as SCM, information systems and finance. The methodology from the data collection aspect is more close to an interview study. Simply, we wish to summarize the previous research in the field, expose it for practitioners, and with help from the cases and the empirical context, elaborate and develop it. The research method can be considered similar to a theory elaborating case study (Ketokivi and Choi, 2014) but relying on less informants per case than usual due to the novel nature of the phenomenon which cause limited availability to the empirical data.

\subsection{Theory Development}

Following Yin (2014), in this study, the first step was theory development with a structured literature study. The current reported BCT applications in SCM were identified, understood, and classified into different applications. The 
systematic literature review process suggested by Petersen $e t$ al. (2008) and guidelines described by Charters and Kitchenham (2007) were used to search for relevant papers (Figure 2). According to Charters and Kitchenham (2007), the systematic mapping process can result in a theoretical framework, rather than a visual systematic map, as done in this study.

\begin{tabular}{|c|c|c|c|c|}
\hline \multicolumn{5}{|l|}{ Process Steps } \\
\hline \begin{tabular}{|c} 
Research Questions \\
Definition
\end{tabular} & $\begin{array}{c}\text { Conduct The } \\
\text { Search }\end{array}$ & $\begin{array}{c}\text { Screening of } \\
\text { Papers }\end{array}$ & $\begin{array}{l}\text { Keywording by } \\
\text { Abstracts (31) }\end{array}$ & $\begin{array}{c}\text { Data Extraction } \\
\text { and Mapping }\end{array}$ \\
\hline Review Scope & $\begin{array}{c}\text { All Papers } \\
(645)\end{array}$ & $\begin{array}{c}\text { Relevant } \\
\text { Papers (206) }\end{array}$ & $\begin{array}{c}\text { Classification } \\
\text { scheme }\end{array}$ & Systematic Map \\
\hline \multicolumn{5}{|l|}{ Outcomes } \\
\hline $\begin{array}{l}\text { Desearch } \\
\text { Questions were } \\
\text { defined as: RQ1 } \\
\text { to RQ5 } \\
\text { The scope is: } \\
\text { peer reviewed } \\
\text { articles based on } \\
\text { the key phrase } \\
\text { "Blockchain and } \\
\text { Supply Chain" }\end{array}$ & $\begin{array}{l}\text { DDifferent databases were } \\
\text { used in the research: } \\
\text { - Ebsco } \\
\text { - ACM Digital Library } \\
\text { - IEEE Xplore } \\
\text { - ScienceDirect } \\
\text { - Springer Link } \\
\text { - Web of Science } \\
\text { - Scopus } \\
\text { - Directory of Open Access } \\
\text { Journals (DOAJ) } \\
\text { DUsed synonym for } \\
\text { "Blockchain" is: } \\
\text { "Decentralized ledger" } \\
\text { DUsed synonyms for "Supply } \\
\text { Chain" are: "Logistics" or } \\
\text { "Physical Distribution" }\end{array}$ & $\begin{array}{l}\text { All } 645 \text { papers } \\
\text { were examined } \\
\text { by screening of } \\
\text { titles, keywords } \\
\text { and abstracts. } \\
\square 439 \text { papers were } \\
\text { found more } \\
\text { relevant to } \\
\text { computer science } \\
\text { and bitcoin } \\
\text { applications } \\
\square 206 \text { paper were } \\
\text { found relevant for } \\
\text { BCT and SCM in } \\
\text { general }\end{array}$ & $\begin{array}{l}\text { U Using Key-wording } \\
\text { by abstracts: } 31 \\
\text { papers were found } \\
\text { relevant for BCT } \\
\text { applications, } \\
\text { drivers, limitations, } \\
\text { success factors and } \\
\text { impacts on SCM } \\
\\
\text { A Classification } \\
\text { scheme by BCT } \\
\text { Application's areas: } \\
\text { - Traceability } \\
\text { - Digitalization } \\
\text { - Compliance } \\
\text { - SC Integration } \\
\text { - SC Finance }\end{array}$ & $\begin{array}{l}\text { DInitial model } \\
\text { components : } \\
\text { - SC Drivers } \\
\text { - BCT Applications } \\
\text { - Limitations } \\
\text { - Success factors } \\
\text { - Impacts on SC } \\
\text { objectives } \\
\text { - Applicability model } \\
\text { DThe Components } \\
\text { were further } \\
\text { investigated } \\
\text { through the case } \\
\text { research }\end{array}$ \\
\hline
\end{tabular}

Figure 2 Systematic literature review process (based on Petersen et al., 2008)

The search and selection resulted initially in 645 titles retrieved from 8 databases based on the main key phrase "blockchain and supply chain," and its synonyms (Figure 2). All the titles were examined by the authors, 439 papers were found more related to computer science than logistics and supply chain management. The remaining papers (206) were found relevant to SCM and BCT in general. The number of papers was further reduced to 31 articles through keywording of abstracts using codes such as: drivers, challenges, success factors, impacts on SC objectives and the different BCT applications. The main two reasons for this high number of excluded articles was that they were not related to the research questions or they were duplicated. The selected articles might seem less in comparison with other studies, but this can be justified as the selection was actually based on the key-wording of abstracts to remove any article that is out of the scope of the study (Charters and Kitchenham, 2007). Therefore, the selected articles were sufficient to draw a theoretical framework and to propose it for practitioners for any further developments.

\subsection{Cases and Data Collection}

The unit of analysis was defined as the BCT applications in SCM. Many cases were selected, and four accepted to participate: IBM and Maersk as a joint project, IBM Global Financing (IGF), Modum, and Volvo Trucks (Table 2). Each case discussed at least some pilot projects regarding BCT in SCM. However, due to limited accessibility, one main informant was interviewed per case. But also, we sent follow-up questionnaires to the informant's colleagues to reduce subjectivity.

Table 2 Case studies data and selection criteria

\begin{tabular}{|lllll|}
\hline Cases & IBM and Maersk & IGF & Modum & Volvo Trucks \\
\hline Company type & $\begin{array}{l}\text { Tech. Provider (IBM) \& } \\
\text { Logistics Services }\end{array}$ & $\begin{array}{l}\text { Financial Organization } \\
\text { (BCT User) }\end{array}$ & $\begin{array}{l}\text { Pharmaceutical Logistics } \\
\text { (Service Provider) }\end{array}$ & $\begin{array}{l}\text { Automotive Industry } \\
\text { (BCT User) }\end{array}$ \\
$\begin{array}{llll}\text { Discussed pilot project? } \\
\text { Available data? }\end{array}$ & Yes & Yes & Yes & Yes \\
Accessible informant? & Yes & Yes & Yes & Yes \\
Main informant role & $\begin{array}{l}\text { Operations Manager, IBM } \\
\text { Innovation Centre. }\end{array}$ & $\begin{array}{l}\text { Operations Manager, } \\
\text { Digital Transformation. }\end{array}$ & Director, Communication Manager, Emerging \\
& & & & Technology. \\
Number of follow-ups & 3 & 3 & 2 & 2 \\
\hline
\end{tabular}


The semi-structured interview protocol followed a funnel model, starting with very open-ended questions regarding the initial theoretical framework in general. Then, we narrowed the scope by asking specific, but still openended, questions related to the first three RQs. Finally, we further narrowed the scope and asked close-ended questions regarding RQs 4 and 5 that are related to the impact on SC objectives and the applicability of each application.

\subsection{Data Analysis and Framework Development}

First, the relevant articles were analyzed to develop an initial theoretical framework in relation to the research questions. This analysis depended on two tactics: open coding and axial coding (Ellram, 1996; Yin, 2014). In open coding, data from articles were broken down, to analyze, conceptualize, and develop categories (Ellram, 1996), to answer RQ1 and RQ2. Then axial coding (pattern analysis) was used to make preliminary connections among the categories developed in open coding (Ellram, 1996) for the first two RQs, and generate insight into the remaining research questions. Thus, the theory was condensed to generate an initial theoretical framework that links different BCT applications with the SC drivers, limitations, success factors, and possible impacts on SC objectives, and to evaluate the applicability of different BCT applications. Open and axial coding are an iterative, rather than sequential process (Ellram, 1996). Once the initial framework was ready, it was analyzed and compared with the data retrieved from the main interviews and the follow-up questionnaires using within-case and cross-case analysis (Eisenhardt, 1989). Thus, the framework was updated and finalized on three stages to be practically relevant, in addition to answering the main research questions.

\subsection{Research Trustworthiness}

Several authors such as Yin (2014), Ellram (1996) and da Mota Pedrosa et al. (2012) suggested many quality criteria to ensure trustworthiness of the case research. Table 3 listed the applied actions relevant to each criteria. Although the measures were taken to increase trustworthiness, we are still aware of the generalizability limitations of our study.

Table 3 Measures taken to ensure case study trustworthiness

\begin{tabular}{|c|c|}
\hline Quality criteria & Applied actions \\
\hline External Validity & $\begin{array}{l}\text { - Multiple cases from different industries are studied } \\
\text { - The theoretical framework is based on studying } 31 \text { articles in which many of them have } \\
\text { addressed different BCT applications in different fields }\end{array}$ \\
\hline Reliability & $\begin{array}{l}\text { - An interview protocol was developed, and used } \\
\text { - A record of interviews was made, and a written details can be provided }\end{array}$ \\
\hline Construct validity & $\begin{array}{l}\text { - Multiple sources of evidence were used (literature, personal interviews and follow-up } \\
\text { questionnaires) } \\
\text { - A chain of events is established by allowing the reader to follow the study from the initial } \\
\text { formulation of the data to its final conclusions } \\
\text { - Feedbacks obtained from key informants with regards to the case description and initial } \\
\text { framework }\end{array}$ \\
\hline Transferability & $\begin{array}{l}\text { - The unit of analysis is justified to be the BCT applications in SCM } \\
\text { - The cases are selected based on defined criteria } \\
\text { - The number of the cases is documented }\end{array}$ \\
\hline Truth-value & $\begin{array}{l}\text { The informants got a chance to correct or confirm the researcher's interpretation of their realities. This } \\
\text { was done through interviews and analysis phase based on the iterative nature of the framework } \\
\text { development }\end{array}$ \\
\hline Traceability & $\begin{array}{l}\text { The documentation of the research process and data sources provides justifications of number of } \\
\text { informants, their roles and place of work }\end{array}$ \\
\hline
\end{tabular}

\section{LITERATURE REVIEW AND COMPONENTS OF THE INITIAL MODEL}

Below, findings from the literature regarding the SC drivers, applications, limitations, success factors, impact on SC objectives, and applicability model of BCT in SCM are discussed. These form a basic component for the theoretical framework.

\subsection{Supply Chain Drivers}

Understanding SC drivers for applying BCT are necessary to know what application a company could use, because different drivers lead to different applications. The axial analysis of literature suggests that the lack of visibility, control, and trust are the essential SC drivers which require additional validation processes (Wang et al., 2019a; Azzi et al., 2019; Montecchi et al., 2019). These essential drivers are general, but they can be cascaded into more specific ones, mentioned in the literature (Table 4). 
Table 4 The most identified SC drivers in the literature

\begin{tabular}{|c|c|}
\hline SC Drivers & References \\
\hline $\begin{array}{l}\text { Products safety issues, especially in the food and pharmaceutical } \\
\text { sectors }\end{array}$ & $\begin{array}{l}\text { (Nakasumi, 2017; Feng, 2017; Tse et al., 2017; Bocek et al., } \\
\text { 2017; Glover and Hermans, 2017; Apte, 2016; Wang et al., } \\
\text { 2019a) }\end{array}$ \\
\hline Data security issues & (Tse et al., 2017; Kshetri, 2017; Saberi et al., 2019) \\
\hline High cost and difficulty of recalls due to quality issues & $\begin{array}{l}\text { (Feng, 2017; Chen et al., 2017; Nakasumi, 2017; Tse et al., } \\
\text { 2017) }\end{array}$ \\
\hline Time-consuming and inefficient manual paperwork & (Kshetri, 2018; Lee and Pilkington, 2017; Azzi et al., 2019) \\
\hline $\begin{array}{l}\text { Information asymmetry in the SC flows, inefficient inventory } \\
\text { management, and double marginalization }\end{array}$ & $\begin{array}{l}\text { (Chen et al., 2017; Wu et al., 2017; Nakasumi, 2017; Kim and } \\
\text { Laskowski, 2018) }\end{array}$ \\
\hline Difficulties with enforcement of regulations & $\begin{array}{l}\text { (Bocek et al., 2017; Apte, 2016; Glover and Hermans, 2017; } \\
\text { Azzi et al., 2019; Min, 2019) }\end{array}$ \\
\hline Fraud issues, such as illegal or counterfeit products in the SC & $\begin{array}{l}\text { (Jabbar and Bjørn, 2018; Kshetri, 2018; Azzi et al., 2019; } \\
\text { Wang et al., 2019a) }\end{array}$ \\
\hline Financial disputes that tie up capital & (O'Leary, 2017; Foerstl et al., 2017; Lee and Pilkington, 2017) \\
\hline $\begin{array}{l}\text { Satisfying consumers by providing transparent products that can be } \\
\text { traced up to its origin }\end{array}$ & $\begin{array}{l}\text { (Kim and Laskowski, 2018; Lu and Xu, 2017; Sahota, 2017; } \\
\text { Saberi et al., 2019; Azzi et al., 2019; Montecchi et al., 2019) }\end{array}$ \\
\hline
\end{tabular}

\subsection{Blockchain Technology Applications in Supply Chain Management}

BCT can be applied to different areas based on the purposes (Yli-Huumo et al., 2016). Many researchers have discussed different applications; for example, Feng (2017), Li et al. (2017), Saberi et al. (2019) and Schmidt and Wagner (2019) discussed applying BCT in SC traceability, and SC integration, among other applications, while Bocek et al. (2017) and Min (2019) discussed applying BCT for compliance with quality standards and digitalization. Furthermore, Lee and Pilkington (2017), O’Leary (2017) suggested using BCT in supply chain finance (SCF). These five applications were the most frequently identified in the literature review, and they are briefly discussed in the following sections.

\subsubsection{Supply Chain Traceability}

SC traceability is defined by ISO $9000: 2000$ as "the ability to trace the history, application or location of that which is under consideration" (Hoyle, 2001). Due to BCT attributes, such as the distributed ledger, peer-to-peer transition, transparency, and irreversibility of records, this BCT application allows for real-time information visibility from a trusted single source of data (Feng, 2017; Kim and Laskowski, 2018; Glover and Hermans, 2017; Jansson and Petersen, 2016; Tse et al., 2017; Feng, 2016; Lu and Xu, 2017; Azzi et al., 2019; Montecchi et al., 2019; Wang et al., 2019b).

\subsubsection{Digitalization of Transactions}

Digitalization goes beyond SC traceability, by utilizing a smart contract feature to execute digital signatures that reduce the number of validation processes based on manual paperwork. The validation processes are reduced, because
BCT provides trusted data from a single source. For example, BCT can be used to execute the digital signatures that are usually made upon predefined terms (Bocek et al., 2017; Popper and Lohr, 2017; Wang et al., 2019a; Azzi et al., 2019).

\subsubsection{Compliance with Standards through Sensors and Smart Contracts}

This application involves using BCT attributes for realtime monitoring and tracking of data to comply with different standards using installed sensors throughout the supply chain (Bocek et al., 2017; Min, 2019). For instance, Modum is a start-up company that utilizes BCT to provide auditable and immutable data that have the potential to positively impact the traceability of medications from the active pharmaceutical ingredient (API) to the patient. BCT can be combined with different sensors to facilitate compliance with different medical regulations concerning the quality of the drugs, such as temperature and humidity throughout the supply chain (Bocek et al., 2017; Azzi et al., 2019). At any failure to meet the quality standards at any step, the defect object automatically fails to move forward in the chain. This procedure is based on predefined terms executed by the smart contract feature (Glover and Hermans, 2017). Compliance can also help other goals, such as sustainability standards in which emissions are monitored and registered on the blockchain, as tested by Volvo (Volvo Trucks, 2017).

\subsubsection{Supply Chain Integration through Smart Contracts}

BCT application in SC integration utilizes all BCT attributes for information sharing across the supply network, but this application differs from traditional integration; as this application enables information sharing through a single trusted source of data rather than integrating various 
enterprise resource planning (ERP) systems. The goal is to achieve effective and efficient flows of products and services, information, money, and decisions, to provide maximum value to the stakeholders (Li et al., 2017; Khan and Wisner, 2019).

Francisco and Swanson (2017) argued that wellintegrated industries and firms may not be willing to substantially invest in new technology that does not provide significant benefits over present solutions. However, Li et al. (2017) contended that there are two key issues in current integration solutions: affordability and real-time visibility of truckload activities. BCT creates a digital thread that tracks the pseudo-real-time status of the shipment, making the physical distribution process completely transparent to stakeholders. Moreover, with smart contracts, used in a fully operating digital environment, there is a possibility of creating algorithms that can be partially or fully executed, or enforced, when certain conditions occur without human interaction. These algorithms drive SC integration into a higher level of efficiency and control than current systems can provide (Li et al., 2017; Schmidt and Wagner, 2019).

\subsubsection{Supply Chain Finance}

The application of BCT in SC finance utilizes BCT attributes to trace and monitor the financial flows and allocation of financial resources in the SC. This application shares and monitors financing-related information, such as latest invoice status, check credit limit and payment in a trusted and transparent manner (Lee and Pilkington, 2017).

It is possible that some self-executing terms are triggered without any human interference, based on the trusted data provided by the blockchain, which can solve financial disputes in the fastest way (O'Leary, 2017). For example, IGF is the world's largest technology financier. It offers an end-to-end portfolio of services and customizable payment plans to help acquire IT business solutions. With a vast network of suppliers and partners, IGF faces major challenges in dispute resolution. There are more than 25,000 disputes every year with 100 million USD in capital tied up at any given time. These disputes occur due to many reasons, such as a lack of end-to-end visibility from invoice to cash, incompatible systems, and no end-to-end view of the progress of goods and payment. King and Nash (2016) stated that applying BCT would provide comprehensive visibility across the entire transaction cycle which would allow stakeholders to prevent or speed up the resolution of disputes.

\subsection{BCT Limitations, Success Factors, and Impact on SC Objectives}

The suggested BCT limitations were scattered among the sources, but none differentiated between the limitations of the different BCT application. Peck (2017) and Lu and Xu (2017) discussed technical limitations, such as throughput, latency, size and bandwidth, usability, versioning, and energy consumption. In contrast, Laaper and Fitzgerald (2017) and Hackius and Petersen (2017) mentioned managerial limitations, such as high cost, privacy and security issues, regulatory uncertainty, different parties have to join forces, lack of technological maturity which enable the resistance of change, lack of acceptance in industry, and not clear benefits. Kshetri (2018), in a more general way, included managerial and technical limitations, such as maturity of sensor devices, the boundary between the physical and virtual worlds, and a high degree of computerization that may not be available in certain countries. In addition, many other literatures have discussed the same limitations but from different perspectives. For example, Saberi et al. (2019) discussed BCT barriers as inter-organizational, intra-organizational, system related and external barriers. But Queiroz and Wamba (2019) discussed similar barriers but from another angles such as: performance expectancy, social influence, facilitating conditions, blockchain transparency and trust among supply chain stakeholders.

Regarding success factors, Peck (2017) listed two factors, the need for trust as an enabler and the availability of extended networks that benefit from the technology. O'Leary (2017) argued that the main success factor is that BCT must deliver a solution that no other cheaper and easier technology could provide. Kim and Laskowski (2018) said that giving incentives for smaller companies to collaborate would enable the success of the technology. Finally, Johansen (2017) mentioned three success factors: to ensure the technology lives up to its promises, to establish innovation within the field by making researchers and practitioners work together, and to cultivate the current ecosystem by supporting developers and users of the platform through strategic initiatives. These success factors were considered for all BCT applications.

In terms of the impact of BCT on SC objectives, Kshetri's (2018) proposed measures such as cost reduction, quality, speed, risk reduction, sustainability and flexibility. These factors can be used for our analysis. (Because no grading of the impact could be found in literature, later in the paper, the impact of these factors is rated numerically, from low (1) to high (5), based on the interview discussions).

\subsection{BCT Applicability Model}

Iansiti and Lakhani (2017) proposed a BCT applicability model based on how the technologies are naturally adopted, depending on the amount of change needed and the amount of complexity and coordination required for implementing it. They suggested four phases: single use, localization, substitution, and transformation (Figure 3).

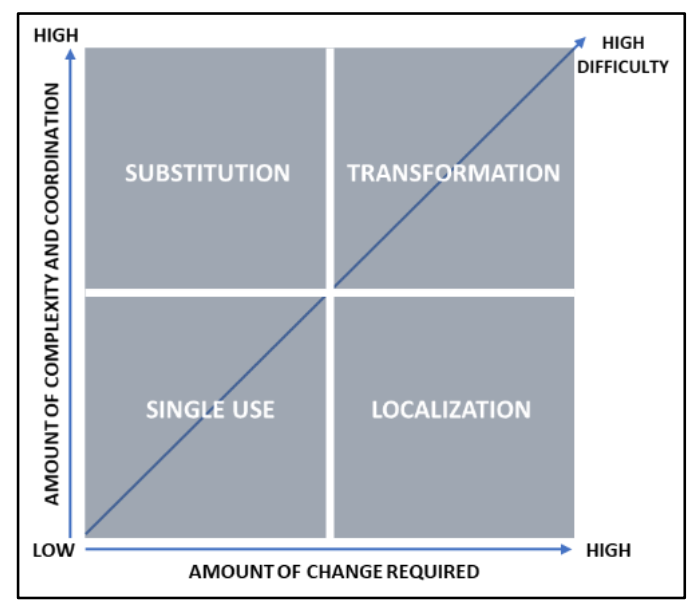

Figure 3 BCT applicability model adopted from Iansiti and Lakhani (2017) 
Single-use applications can be implemented immediately, such as applying BCT to help organizations build an internal database. Localized solutions involve only a single or a few trusted counterparties, it can be developed to simplify transactions. Iansiti and Lakhani (2017) argued that localized applications could be tested, if they seem promising before they are implemented. Substitutive applications may replace current processes in an organization. Thus, substitutive applications might demand users to change some behaviors. They also argued that "being unable to communicate similar or better functionality of the new application might prevent substitutive technology adoption" (Iansiti and Lakhani, 2017). Finally, transformative technology applications require a high degree of coordination, in addition to social, legal, and political changes (Iansiti and Lakhani, 2017). Smart contracts, for example, could possibly be a transformative technology. Iansiti and Lakhani (2017) elaborated that "a tremendous degree of coordination and clarity on how smart contracts are designed, verified, implemented, and enforced will be required." Thus, smart contracts are far from being implemented in the meantime, especially in full utilization.

\section{RESULTS AND ANALYSIS}

During the interviews, the different SC drivers, limitations, and success factors from previous literature were further explored with the respondents for each BCT application (Figure 4). Not all the cases experienced all five applications. IBM and Maersk as a joint project applied BCT in SC traceability, compliance, digitalization, and SC integration, but not in SC finance. Modum applied BCT in compliance and digitalization, and Volvo Trucks tested BCT in compliance and SC traceability. IBM Global Finance applied BCT only in SC finance.

\begin{tabular}{|c|c|c|c|c|c|c|c|c|c|c|c|c|c|c|c|}
\hline & Framework Aspects / BCT Applications & SC Tr & racea & jility & & $\mathrm{mpl}$ & iance & & Digit & aliza & tion & SC Integ & ation & SCF & iance \\
\hline & $\begin{array}{l}\text { I\&M=IBM \& MAERSK || V=Volvo || M=Modum } \\
\text { IGF= IBM Global Finance || FI=Follow-up Interview ] }\end{array}$ & I\&M & $\mathrm{V}$ & FI & I\&M & $\mathrm{v}$ & M & $\mathrm{FI}$ & I\&M & $\mathrm{M}$ & $\mathrm{FI}$ & I\&M & $\mathrm{FI}$ & IGF & FI \\
\hline & Products safety (or quality*) issues & $\checkmark$ & - & $\checkmark$ & $\checkmark$ & - & $\checkmark$ & $\checkmark$ & - & - & - & - & - & - & - \\
\hline & Data security issues & $\checkmark$ & - & $\checkmark$ & - & - & - & - & - & - & $\checkmark$ & - & - & - & - \\
\hline & High cost and difficulty of recalls due to quality issues & $\checkmark$ & $\checkmark$ & $\checkmark$ & & & & & - & - & - & - & - & - & - \\
\hline & Time consuming and inefficient manual paper work & - & - & - & - & - & - & $\checkmark$ & $\checkmark$ & $\checkmark$ & $\checkmark$ & - & $\underline{v}$ & - & $\underline{v}$ \\
\hline$\cong$ & Information asymmetry along the SC flows & $\checkmark$ & $\checkmark$ & $\checkmark$ & - & - & - & - & - & - & - & $\checkmark$ & $\checkmark$ & - & $\underline{v}$ \\
\hline$\stackrel{\bar{\nu}}{\geq}$ & Inefficient inventory management & - & - & - & - & - & - & - & - & - & - & $\checkmark$ & $\checkmark$ & - & - \\
\hline 穴 & Double marginalization problems & - & - & - & - & - & - & - & - & - & - & $\checkmark$ & $\checkmark$ & - & - \\
\hline & High cost and difficulties with regulations enforcement & - & - & - & $\checkmark$ & $\checkmark$ & $\checkmark$ & $\checkmark$ & - & - & - & - & - & - & - \\
\hline & Fraud issues such as illegal or counterfeited data and products & $\checkmark$ & $\checkmark$ & $\checkmark$ & $\checkmark$ & $\checkmark$ & $\checkmark$ & $\checkmark$ & - & - & $\checkmark$ & - & - & - & - \\
\hline & Financial disputes that cause tied up capital & - & - & - & - & - & - & - & - & - & - & - & - & $\checkmark$ & $\checkmark$ \\
\hline & Provenance (or transparency*) value to consumers & $\checkmark$ & $\checkmark$ & $\checkmark$ & - & - & - & - & - & - & - & - & - & - & - \\
\hline & Sustainability issues* & - & $\checkmark$ & $\checkmark$ & - & $\checkmark$ & - & $\checkmark$ & - & - & - & - & - & - & - \\
\hline & High investment cost & - & - & - & $\checkmark$ & $\checkmark$ & - & $\checkmark$ & - & - & - & $\checkmark$ & $\bar{\checkmark}$ & - & - \\
\hline & Lack of acceptance in industry & $\checkmark$ & $\checkmark$ & $\checkmark$ & $\checkmark$ & $\checkmark$ & $\checkmark$ & $\checkmark$ & $\checkmark$ & $\checkmark$ & $\checkmark$ & $\checkmark$ & $\checkmark$ & $\checkmark$ & $\checkmark$ \\
\hline & Different parties have to join forces & $\checkmark$ & $\checkmark$ & $\checkmark$ & $\checkmark$ & $\checkmark$ & $\checkmark$ & $\checkmark$ & $\checkmark$ & $\checkmark$ & $\checkmark$ & $\checkmark$ & $\checkmark$ & $\checkmark$ & $\checkmark$ \\
\hline & Privacy and data security issues & $\checkmark$ & $\checkmark$ & $\checkmark$ & $\checkmark$ & $\checkmark$ & $\checkmark$ & $\checkmark$ & $\checkmark$ & $\checkmark$ & $\checkmark$ & $\checkmark$ & $\checkmark$ & $\checkmark$ & $\checkmark$ \\
\hline$\check{c}_{0}$ & Regulatory uncertainty & $\checkmark$ & $\checkmark$ & $\checkmark$ & $\checkmark$ & $\checkmark$ & $\checkmark$ & $\checkmark$ & $\checkmark$ & $\checkmark$ & $\checkmark$ & $\checkmark$ & $\checkmark$ & $\checkmark$ & $\checkmark$ \\
\hline 焉 & Lack of technological maturity & $\checkmark$ & $\checkmark$ & $\checkmark$ & $\checkmark$ & $\checkmark$ & $\checkmark$ & $\checkmark$ & $\checkmark$ & $\checkmark$ & $\checkmark$ & $\checkmark$ & $\checkmark$ & $\checkmark$ & $\checkmark$ \\
\hline$\overline{\bar{E}}$ & Benefits are not clear & - & $\checkmark$ & $\checkmark$ & - & - & - & - & $\checkmark$ & $\checkmark$ & $\checkmark$ & $\checkmark$ & $\checkmark$ & $\checkmark$ & $\checkmark$ \\
\hline & Maturity of IOT, RFID and Sensor devices & - & - & - & $\checkmark$ & $\checkmark$ & $\checkmark$ & $\checkmark$ & - & - & - & $\checkmark$ & $\checkmark$ & - & - \\
\hline & High degree of computerization (or infrastructure*) & - & - & - & $\checkmark$ & $\checkmark$ & - & $\checkmark$ & - & - & - & $\checkmark$ & $\checkmark$ & - & - \\
\hline & Boundaries between physical and Digital Flows & $\checkmark$ & $\checkmark$ & $\checkmark$ & - & - & - & - & - & - & - & $\checkmark$ & $\checkmark$ & - & - \\
\hline & Technical Challenges & $\checkmark$ & $\checkmark$ & $\checkmark$ & $\checkmark$ & $\checkmark$ & $\checkmark$ & $\checkmark$ & $\checkmark$ & $\checkmark$ & $\checkmark$ & $\checkmark$ & $\checkmark$ & $\checkmark$ & $\checkmark$ \\
\hline & Ensure Trust is essential to the organization & $\checkmark$ & $\checkmark$ & $\checkmark$ & $\bar{\checkmark}$ & $\checkmark$ & $\checkmark$ & $\checkmark$ & $\checkmark$ & $\checkmark$ & $\checkmark$ & $\bar{\checkmark}$ & $\checkmark$ & $\checkmark$ & $\checkmark$ \\
\hline & An extended network to benefit from the technology & $\checkmark$ & $\checkmark$ & $\checkmark$ & $\checkmark$ & $\checkmark$ & $\checkmark$ & $\checkmark$ & $\checkmark$ & $\checkmark$ & $\checkmark$ & $\checkmark$ & $\checkmark$ & $\checkmark$ & $\checkmark$ \\
\hline & No other solutions give the same benefits & $\checkmark$ & $\checkmark$ & $\checkmark$ & $\checkmark$ & $\checkmark$ & $\checkmark$ & $\checkmark$ & $\checkmark$ & $\checkmark$ & $\checkmark$ & $\checkmark$ & $\checkmark$ & $\checkmark$ & $\checkmark$ \\
\hline ñ & Incentive to collaborate for smaller companies & $\checkmark$ & $\checkmark$ & $\checkmark$ & $\checkmark$ & $\checkmark$ & $\checkmark$ & $\checkmark$ & $\checkmark$ & $\checkmark$ & $\checkmark$ & $\checkmark$ & $\checkmark$ & $\checkmark$ & $\checkmark$ \\
\hline \begin{tabular}{|l}
$\stackrel{u}{\pi}$ \\
$\stackrel{4}{L}$
\end{tabular} & Ensure technology lives up to promised features & $\checkmark$ & $\checkmark$ & $\checkmark$ & $\checkmark$ & $\checkmark$ & $\checkmark$ & $\checkmark$ & $\checkmark$ & $\checkmark$ & $\checkmark$ & $\checkmark$ & $\checkmark$ & $\checkmark$ & $\checkmark$ \\
\hline$\breve{u}$ & Establish innovation within the field & $\checkmark$ & $\checkmark$ & $\checkmark$ & $\checkmark$ & $\checkmark$ & $\checkmark$ & $\checkmark$ & $\checkmark$ & $\checkmark$ & $\checkmark$ & $\checkmark$ & $\checkmark$ & $\checkmark$ & $\checkmark$ \\
\hline$\stackrel{u}{u}$ & Organizations Support developers and users of the platform & $\checkmark$ & $\checkmark$ & $\checkmark$ & $\checkmark$ & $\checkmark$ & $\checkmark$ & $\checkmark$ & $\checkmark$ & $\checkmark$ & $\checkmark$ & $\checkmark$ & $\checkmark$ & $\checkmark$ & $\checkmark$ \\
\hline & Governmental support for regulation and funding* & $\checkmark$ & - & $\checkmark$ & $\checkmark$ & - & - & $\checkmark$ & - & - & $\checkmark$ & $\checkmark$ & $\checkmark$ & $\checkmark$ & $\checkmark$ \\
\hline & Published standardized practices for benchmarking* & - & $\checkmark$ & $\checkmark$ & - & $\checkmark$ & - & $\checkmark$ & $\checkmark$ & - & $\checkmark$ & - & $\underline{v}$ & - & $\underline{v}$ \\
\hline & Availability of skilled labor* & - & - & $\underline{v}$ & - & - & $\checkmark$ & $\checkmark$ & - & $\checkmark$ & $\checkmark$ & - & $\checkmark$ & - & $\underline{v}$ \\
\hline
\end{tabular}

Figure 4 Case study results for SC drivers, limitations, and success factors 
The SC drivers and the limitations identified from the literature did not fit all BCT applications, but all the success factors were confirmed for all BCT applications. In addition, three success factors and one SC driver (Marked with a star *) were not discovered in the literature, only in the interviews. There were also some differences between companies within the same case. However, with the followup questionnaires, the subjectivity were reduced using a rating mean calculation to confirm an answer. The underlining marks in Figure $\mathbf{4}$ mean that the aspect itself was not mentioned in the interviews with the main informant, but instead received a high rating mean through the follow-up questionnaires.

To understand the impacts on SC objectives, each objective was measured with respect to the different BCT applications (Figure 5). The measurement scale used in the main interviews and the follow-up questionnaires ranged from 1 ("low impact") to 5 ("high impact").

SC integration had the highest impact on SC objectives, followed by compliance, digitalization, SC traceability, and $\mathrm{SC}$ finance. These results were justified by the high impact of SC integration on cost, quality, and speed. Applying BCT in SC integration reduces high costs by reducing inventory capacity risks.

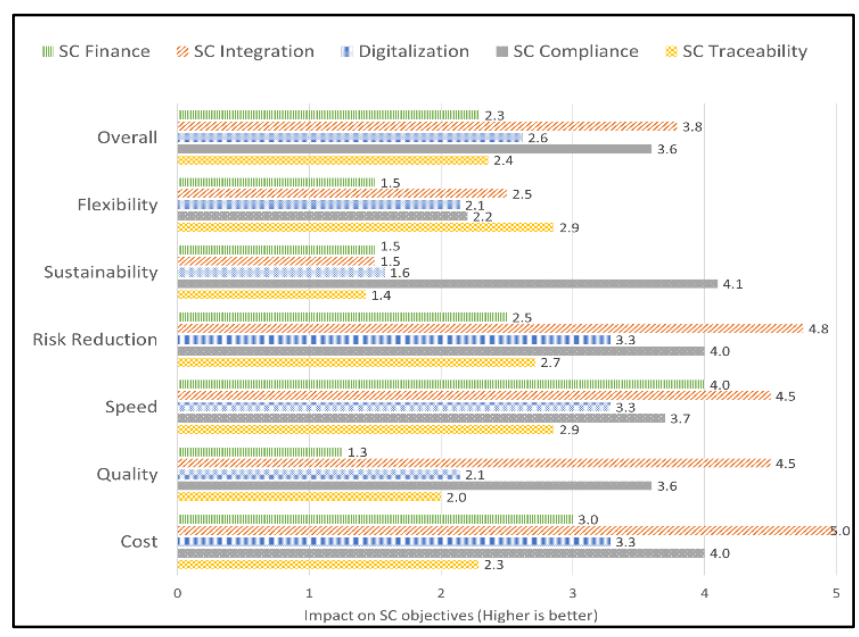

Figure 5 Impact on SC objectives

BCT also affects quality, as deliveries are timelier and more visible, as well as speed, due to autonomous decisions based on smart contracts. However, SC integration had a low impact on flexibility, because integration could be limited by smart contracts. Second to SC integration was SC compliance, which had a high overall impact, mainly driven by the impact on sustainability (Sustainability was slightly affected by other applications except SC compliance). Moreover, SC compliance had a high impact on cost, quality, speed, and risk reduction, because it can solve regularity issues, and comply with the highest standards in term of quality or sustainability. Next, digitalization had a slightly higher overall impact than SC traceability and SC finance, but much lower than SC integration and SC compliance. This impact was mainly driven by the decreased cost of manual paperwork and its required labor.

Although SC traceability was lower in overall impact, it does not mean it had no impact at all. Indeed, SC traceability was applied in a proof of concept at IBM and Maersk, and showed an impact in cost, quality, speed, risk reduction, and sustainability. However, when compared to other applications, such as SC integration and SC compliance, the impact of SC traceability was much lower. SC finance is considered a limited application that is a part of SC traceability, to solve exact issues such as tied-up capital and financial disputes. Therefore, it is natural that SC Finance has less impact on SC objectives. Overall, BCT has an impact on SC objectives, but the impact differed among different BCT applications.

Based on the interviews, we outlined the views on the applicability of different BCT applications using the rating means for two elements: the amount of change required to apply BCT and the amount of complexity and coordination for each application (Figure 6). (1 means "very low," and 5 means "very high.").

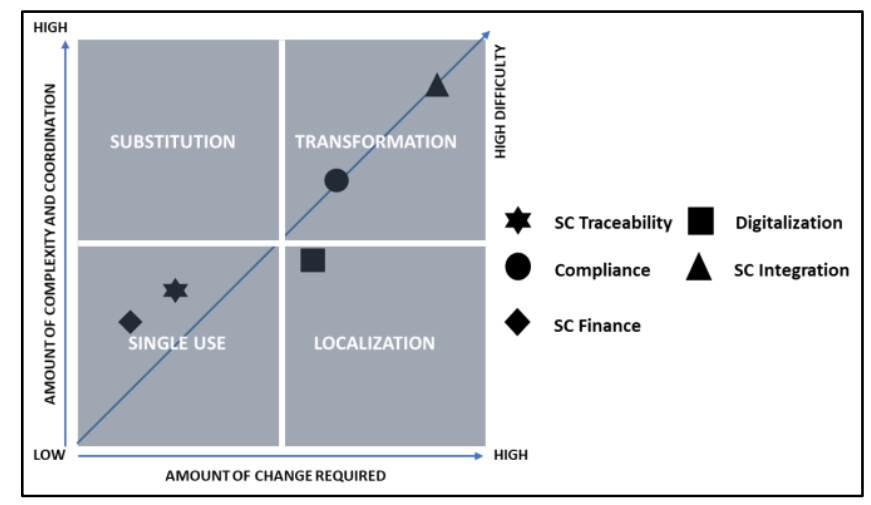

Figure 6 Applicability results

SC finance and SC traceability were confirmed to be single-use applications, as they require a lower amount of change and coordination comparatively. This means they can be applied immediately. During the analysis, the position of digitalization shifted many times, and at the beginning, was difficult to categorize. Finally, digitalization was considered a localized application which means it can be applied if it seems promising. SC compliance and SC integration were transformation applications, which normally require social, legal, and political changes, in addition to a tremendous degree of coordination in how smart contracts should be designed, verified, implemented, and enforced. Thus, these applications seem far from being implemented in the meantime.

\section{FRAMEWORK DEVELOPMENT AND DISCUSSION}

Based on the above analysis and discussions, the theoretical framework (Figure 7) was further developed. It utilizes common problem-solving steps: Identify, Select, Create, and Evaluate (Beecroft et al., 2003) to guide organizations (interested in applying BCT) in their analysis. These steps are iterative, and can occur in cycles, in which each one represents a new pilot project. The framework consists of upper and lower halves. The upper half represents a holistic or strategic view companies should use, while the lower half represents tactical details for each BCT application to consider. The index number in the upper half (for each SC driver, limitation, success factor, and possible impact on SC objectives) is used in the lower part of the framework to link the different constructs together. The 
following discussion both refers to the potential practical use of the framework, and the initial research questions as the framework helped in answering them.

In the first step, the SC drivers relevant for the organization should be identified. The SC drivers outlined in the framework are the most commonly retrieved from the theory and case discussions, and of course, are not exclusive, as different organizations could have their own. In fact, some SC drivers have potential for many BCT applications, such as inefficient and time-consuming manual paperwork. Here, the potential SC driver can be seen from different points of view. In digitalization, for example, the driver could be manual transactional operations, while in SC integration, the driver could be the manual work for managing inventories; in SC compliance, the driver could be quality checks throughout the SC, and in SC finance, the driver could be the financial paperwork and billing operations. The same applies to fraud issues, for example, it is a potential SC driver for applying BCT in SC traceability, but it could be further enhanced if it were applied in SC compliance and digitalization, as these applications go beyond visibility to give further autonomous control.

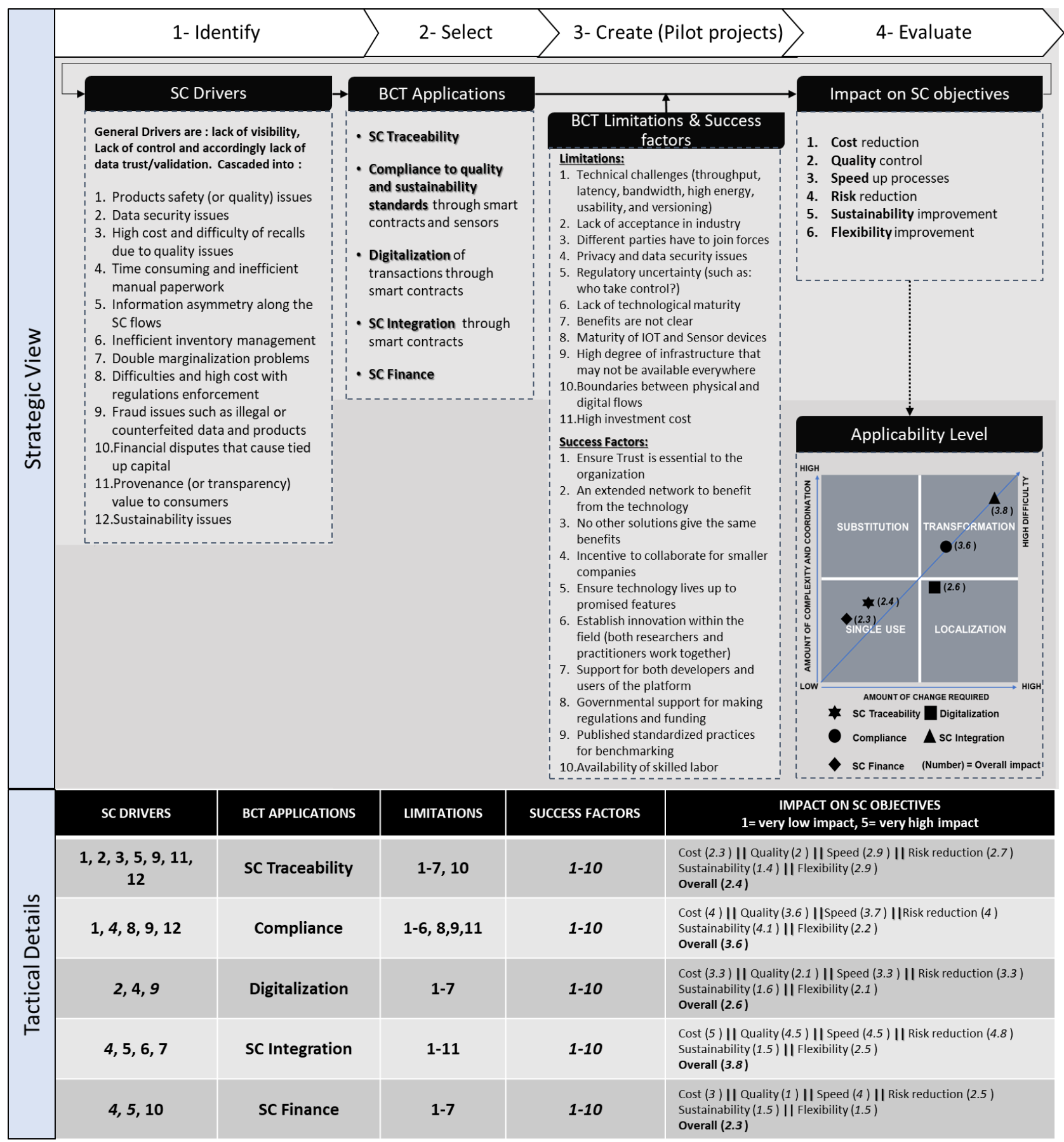

Figure 7 Theoretical framework

The first research question (What are the drivers for using BCT in SCM?) is answered in the first step (Identify). The axial analysis of literature suggests that the lack of visibility, control, and trust are the general SC drivers as it leads the system to require additional validation processes (e.g. Casey and Wong, 2017; Peck, 2017; Kshetri, 2017). The lack of trust in particular is a result of the lack of visibility and control (Wang et al., 2019a; Azzi et al., 2019; 
Montecchi et al., 2019). The framework goes beyond that and lists 12 specific SC drivers retrieved from theory but also updated and validated through the interviews. All the specific drivers are connected directly or indirectly to the general ones.

In the second step (Select), the main current BCT applications in SCM are introduced, and should be understood to make a platform for analysis. The second research question (What are the BCT applications in SCM?) is clearly answered here, as five major applications of BCT in SCM were found: SC traceability, digitalization, compliance, SC integration, and SC finance.

The third step (Create) indicates that companies typically apply small pilot projects to test and verify results before scaling up. The major concern was not to monitor the operational and technical obstacles, but to look for the strategic limitation and success factors. Several similar limitations were found among all BCT applications examined, such as technical challenges, lack of acceptance, different parties have to join forces, privacy and data security, regulatory uncertainty, and immaturity of the technology. However, in the compliance application, the benefits of the BCT were clearly defined unlike all other applications in which the benefits were not very clear to everyone. Indeed, applying BCT in SC Integration and compliance seems to be more challenging as they require more mature infrastructures and sensor devices than applying BCT in traceability, digitalization and SC Finance. Unlike the limitations, the success factors of applying BCT in SCM seemed to be general to all applications based on the literature and confirmed by the case discussions.

The third research question (What are the limitations and success factors of applying BCT in SCM?) was answered in the third step. Eleven limitations are listed and matched with different BCT applications followed by 10 general success factors for all the BCT applications.

The fourth step (Evaluation) includes two parts. First, the impact on SC objectives should be understood, and second, the applicability level assessed, which is the result of all the previous steps. For the impact on SC objectives, six major objectives were seen to be rational: cost reduction, quality, speed, risk reduction, sustainability, and flexibility. Each BCT application had a different level of impact on the different objectives. In the applicability model, it was obvious that the higher-impact applications (SC integration and compliance) were more difficult and less applicable than those with lower impact. This step also provides clear answers to the fourth and fifth research questions (What is the impact of each BCT application on SC objectives? To what extent is BCT applicable in the SCM field?).

On a general note, all respondents found that the framework's steps and components were easy to understand, and effective. Some notes and recommendations, such as clarifying the iteration explicitly, were considered in the final framework. Thus, the framework fulfilled the purpose of this study to identify and explore different applications of BCT in SCM and can help interested organizations in their analysis.

\section{FUTURE RESEARCH}

Although one direction for future research is to continue to generally study BCT applications, another is to go deeper into the technicalities of SCM applications. Indeed, the developed framework could lead into some interesting future research propositions.

In terms of SC drivers, the main research questions that are still remain uncovered or not fully understood are mostly related to trust issues. BCT and trust seem to have a doublesided relation: Trust is a driver, as BCT is argued to handle the trust issue in SCM. For example, Peck (2017) argued that $\mathrm{BCT}$ is not needed at all if there is an absolute trust among the supply chain partners and the third party. However, it is acknowledged that trust is a success factor for BCT implementation, and for supply chain information sharing in general. Thus, this dual relationship between trust and BCT would be an interesting area for future research: What elements of trust are needed, and what parts of BCT could increase which elements of trust? Is the current traditional ways of developing trust between SC partners will be obsolete if BCT is adopted? Even if BCT could guarantee trusted and fully visible information, can we trust the technology?

The second step in the framework raises an important question and research area regarding BCT applications in SCM. As different firms could use the technology to accomplish different goals; is the technology a substitute to the current information and communication systems? Or is it a complementary of the current systems? Furthermore, does applying BCT in SCM will eliminate the need of intermediaries in the chain? If so, is there any new intermediaries could occur? Does this differ from one application to another? And what factors could affect this?

Regarding the third step, knowing and understanding BCT limitations and success factors will defiantly lead to more design questions, mainly to ask if the scalability of $\mathrm{BCT}$ is possible. Also, setting standards and governance mechanisms for using BCT in SCM would be an interesting research as regulatory uncertainty is proved to be a major limitation.

Finally, understanding the impact of BCT on SC objectives will raise questions to answer if the investment is needed for such a change. It will be interesting to compare between current information systems and BCT from different angels to put the technology in the right position despite the hype it gets currently (Van Hoek, 2019).

\section{CONTRIBUTIONS AND LIMITATIONS OF THE RESEARCH}

Blockchain technologies are currently promoted to be important for the supply chain field, but there is limited evidence for this, and studies of BCT applications in SCM other than SC traceability are lacking in the literature. For example, Lee and Pilkington, (2017) pointed out different BCT applications but with no clear distinguish between them in term of their different SC drivers. Peck (2017), Lu and Xu (2017), Hackius and Petersen (2017), Kshetri (2018), Saberi et al (2019), Queiroz and Wamba, (2019), Wang et al (2019a) and Min (2019) have all discussed different BCT limitations without considering its different applications. This research contributes by providing a framework that can support organizations in analyzing and differentiating between different BCT applications. This was done by providing a holistic perspective, including SC drivers, limitations, success factors, and the impact on SC objectives 
for each BCT application. This was, to our knowledge, not done before and can be the basis for further comparisons and exploratory studies. Moreover, Iansiti and Lakhani (2017) provided an applicability model for BCT as a whole, while this research provides evidence to help researchers understand that BCT adoption differs from one BCT application to another.

For practitioners, this study contributes with a framework that provides insights into what to expect before starting an implementation. The framework can guide and aid organizations to understand what BCT offers for their supply chains, and which BCT applications might be implemented according to the organizations' needs.

For the society, applying BCT can be seen as a relationship building tool between organizations and its consumers. When the consumers can trace their products up to the origin, it will increase their trust into what they are buying. This study shows that applying BCT in tractability can be done in the meantime, which might affect the society if it could enhance the consumer's behaviors toward more sustainable decisions (Saberi et al., 2019).

All studies have limitations. First, as the research maturity in this field is low, no exact definitions for BCT applications in the SCM field were found, except different views. The technology and its applications are still new and fresh, and developing quickly. This means that new interesting cases and applications should be developed continuously, providing nearly unlimited opportunities to test, update, and challenge our proposed findings and framework. However, a problem, and a limitation of this study, is still accessibility to empirical data. Not many cases in the market have implemented or finalized pilot projects, and few are willing to participate and share insights. Many comments on the topic are from technology providers or start-ups trying to "sell" the concept. We identified some valuable cases, but due to confidentiality reasons, they were not reachable. Investigating only four cases is clearly a limitation, and that caused some BCT applications to be represented by a single company (e.g., SC finance and SC integration). As the BCT field move fast forward, a study (both related to literature reviewed and available cases) somehow get old during a long and rigorous research and review process.

A related limitation of this study is the high reliance on the literature review, because there were fewer cases to study. This, of course, leads to the question, whether the findings are complete. For example, the commonly identified SC drivers, applications, limitations, and success factors might not be the most important ones in practice, because the most newly discovered are mentioned less frequently. This is a major limitation, as literature does not always accurately reflect practice besides the selected literatures might be less in comparison to other studies. Therefore, it was important to gain practitioners' trust through interviews. A limitation related to the case study method, was the limited number of respondents for each case, making the data collection part more similar to an interview study. But the analysis followed a multiple case study approach. However, as the empirical data were limited; thus, future research should aim to critically study the phenomenon with rigorous methods and much more empirical data to challenge these results, and to complement the literature that mostly hypes the concept.

\section{REFERENCES}

Apte, S. (2016), Will blockchain technology revolutionise excipient supply chain management?. Journal of Excipients and Food Chemicals, 7 (3), pp. 76-78.

Azzi, R., Chamoun, R.K. and Sokhn, M. (2019), The power of a blockchain-based supply chain. Computers \& Industrial Engineering, 135, pp. 582-592.

Beecroft, G., Duffy, G. and Moran, J. (2003), The executive guide to improvement and change. ASQ Quality Press, Milwaukee, Wis.

Bocek, T., Rodrigues, B., Strasser, T. and Stiller, B. (2017), Blockchains everywhere - a use-case of blockchains in the pharma supply-chain. In 2017 IFIP/IEEE Symposium on Integrated Network and Service Management (IM), IEEE, New York, USA, pp. 772-777.

Casey, M. and Wong, P. (2017), Global supply chains are about to get better, thanks to blockchain, Harvard Business Review, 13 March, available at: https://hbr.org/2017/03/globalsupply-chains-are-about-to-get-better-thanks-to-blockchain (accessed 3 January 2019).

Charters, S. and Kitchenham, B. (2007), Guidelines for performing systematic literature reviews in software engineering, EBSE Technical Report, Durham, UK.

Chen, S., Shi, R., Ren, Z., Yan, J., Shi, Y. and Zhang, J. (2017), A blockchain-based supply chain quality management framework. In 2017 IEEE 14th International Conference on e-Business Engineering (ICEBE), IEEE, New York, USA, pp. 172-176.

Da Mota Pedrosa, A., Näslund, D. and Jasmand, C. (2012), Logistics case study based research: towards higher quality. International Journal of Physical Distribution and Logistics Management, 42 (3), pp. 275-295.

Eisenhardt, K.M. (1989), Building theories from case study research. Academy of Management Review, 14 (4), pp. 532550.

Ellram, L.M. (1996), The use of the case study method in logistics research. Journal of Business Logistics, 17 (2), pp. 93-138.

Feng, T. (2016), An agri-food supply chain traceability system for China based on RFID and blockchain technology. In 13th International Conference on Service Systems and Service Management (ICSSSM) in Kunming, China, IEEE, New York, USA, pp. 1-6.

Feng, T. (2017), A supply chain traceability system for food safety based on HACCP, blockchain and Internet of things. In 2017 International Conference on Service Systems and Service Management in Dalian, China, IEEE, New York, USA, pp. 16.

Foerstl, K., Schleper, M.C. and Henke, M. (2017), Purchasing and supply management: from efficiency to effectiveness in an integrated supply chain. Journal of Purchasing and Supply Management, 23 (4), pp. 223-228.

Francisco, K. and Swanson, D. (2018), The Supply Chain Has No Clothes: Technology Adoption of Blockchain for Supply Chain Transparency. Logistics, 2 (1), pp. 2-3.

Glover, D.G. and Hermans, J. (2017), Improving the traceability of the clinical trial supply chain. Applied Clinical Trials, 26 (12), pp. 36-38.

Groenfeldt, T. (2017), IBM and Maersk apply blockchain to container shipping. Forbes, 5 March, available at: www.forbes.com/sites/tomgroenfeldt/2017/03/05/ibm-andmaersk-applyblockchain-to-containershipping/\#435edc743f05 (accessed 2 January, 2019).

Gurtu, A. and Johny, J. (2019), Potential of blockchain technology in supply chain management: a literature review. International Journal of Physical Distribution \& Logistics Management, 49 (9), pp. 881-900

Hackius, N. and Petersen, M. (2017), Blockchain in logistics and supply chain: trick or treat?. In Hamburg International 
Conference of Logistics (HICL), Epubli, Hamburg, Germany, pp. 3-18.

Hoyle, D. (2001), ISO 9000 Quality Systems Handbook, British Library, London, England.

Iansiti, M. and Lakhani, K.R. (2017), The truth about blockchain. Harvard Business Review, 1 January, pp. 118-127. Available at: $\quad$ https://hbr.org/2017/01/the-truth-about-blockchain (accessed 3 January 2019).

Jabbar, K. and Bjørn, P. (2018), Infrastructural grind: introducing blockchain technology in the shipping domain. In Proceedings of the 2018 ACM Conference on Supporting Groupwork, ACM, New York, NY, pp. 297-308.

Jansson, F. and Petersen, O. (2016), Blockchain technology in supply chain traceability systems, Lund University. Available at: https://lup.lub.lu.se/studentpapers/search/publication/8918347 (accessed 5 January 2019).

Johansen, S.K. (2017), A comprehensive literature review on the blockchain technology as a technological enabler for innovation. Working paper, Mannheim University, Department of Information Systems, 1 November.

Ketokivi, M. and Choi, T. (2014), Renaissance of case research as a scientific method. Journal of Operations Management, 32 (5), pp. 232-240.

Khan, H. and Wisner, J.D. (2019), Supply chain integration, learning, and agility: effects on performance. Operations and Supply Chain Management, 12 (1), pp. 14-23.

Kim, H.M. and Laskowski, M. (2018), Toward an ontology-driven blockchain design for supply-chain provenance. Intelligent Systems in Accounting, Finance \& Management, 25 (1), pp. 18-27.

King, R. and Nash, K.S. (2016), IBM set to launch one of the largest blockchain implementations to date. The Wall Street Journal, available at: https://blogs.wsj.com/cio/2016/07/29/ibm-setto-launch-one-of-the-largest-blockchain-implementationsto-date/ (accessed 1 January 2019).

Kshetri, N. (2017), Blockchain's roles in strengthening cybersecurity and protecting privacy. Telecommunications Policy, 41 (10), pp. 1027-1038.

Kshetri, N. (2018), Blockchain's roles in meeting key supply chain management objectives, International Journal of Information Management, 39, pp. 80-89.

Lambert, D.M. and Enz, M.G. (2017), Issues in supply chain management: progress and potential, Industrial Marketing Management, 62, pp. 1-16.

Laaper, S. and Fitzgerald, J. (2007), Using blockchain to drive supply chain innovation. Available at: https://www2.deloitte.com/us/en/pages/operations/articles/bl ockchain-supply-chain-innovation.html (accessed 10 January 2019).

Lee, J.H. and Pilkington, M. (2017), How the blockchain revolution will reshape the consumer electronics industry. IEEE Consumer Electronics Magazine, 6 (3), pp. 19-23.

Li, Z., Wu, H., King, B., Miled, Z. B., Wassick, J. and Tazelaar, J. (2017), On the integration of event-based and transactionbased architectures for supply chains. In 2017 IEEE 37th International Conference on Distributed Computing Systems Workshops, IEEE, New York, USA, pp. 376-382.

Loop, P. (2016), Blockchain: the next evolution of supply chains. Material Handling \& Logistics, pp. 22-24. Available at: https://www.mhlnews.com/global-supplychain/article/22052455/blockchain-the-next-evolution-ofsupply-chains (accessed 1 January 2019)

Lu, Q. and Xu, X. (2017), Adaptable blockchain-based systems: a case study for product traceability. IEEE Software, 34 (6), pp. 21-27.

Mentzer, J.T., Dewitt, W., Keebler, J.S., Min, S., Nix, N.W., Smith, C.D. and Zacharia, Z.G. (2001), Defining supply chain management, Journal of Business Logistics, 22 (2), pp. 1-25.
Min, H. (2019), Blockchain technology for enhancing supply chain resilience, Business Horizons, 62 (1), pp. 35-45,

Montecchi, M., Plangger, K., Etter, M. (2019), It's real, trust me! Establishing supply chain provenance using blockchain Business Horizons, 62 (3), pp. 283-293

Nakamoto, S. (2008), Bitcoin: a peer-to-peer electronic cash system. Available at: https://bitcoin.org/bitcoin.pdf (accessed 2 January 2019).

Nakasumi, M. (2017), Information sharing for supply chain management based on blockchain technology. In IEEE 19th Conference on Business Informatics, IEEE, New York, USA, pp. 140-149.

O'Leary, D.E. (2017), Configuring blockchain architectures for transaction information in blockchain consortiums: the case of accounting and supply chain systems. Intelligent Systems in Accounting, Finance and Management, 24 (4), pp. 138-147.

Peck, M. E. (2017), Blockchain world - Do you need a Blockchain? This chart will tell you if the technology can solve your problem. IEEE Spectrum, 54 (10), pp. 38-60.

Petersen, K., Feldt, R., Mujtaba, S. and Mattsson, M. (2008), Systematic mapping studies in software engineering. In Proceedings of the 12th international conference on Evaluation and Assessment in Software Engineering, Ease publication, UK, pp. 68-77.

Popper, N. and Lohr, S. (2017), Blockchain: a better way to track pork chops, bonds, bad peanut butter. New York Times, 4 March, pp. 4.

Queiroz, M. and Wamba, S. (2019), Blockchain adoption challenges in supply chain: An empirical investigation of the main drivers in India and the USA. International Journal of Information Management, 46, pp.70-82.

Saberi, S., Kouhizadeh, M., Sarkis, J. and Shen, L. (2018), Blockchain technology and its relationships to sustainable supply chain management. International Journal of Production Research, 57 (7), pp.2117-2135.

Sahota, J. (2017), Supply chain exposed. Alternatives Journal, 43 (2), p. 11

Schmidt, C. and Wagner, S. (2019), Blockchain and supply chain relations: A transaction cost theory perspective. Journal of Purchasing and Supply Management, 25 (4), 100552.

Treiblmaier, H. (2018), The impact of the blockchain on the supply chain: a theory-based research framework and a call for action. Supply Chain Management An International Journal, 23 (6), pp. 545-559.

Tse, D., Zhang, B., Yang, Y., Cheng, C. and Mu, H. (2017), Blockchain application in food supply information security. In 2017 IEEE International Conference on Industrial Engineering and Engineering Management (IEEM), IEEE, New York, USA, pp. 1357-1361.

Van Hoek, R. (2019), Exploring blockchain implementation in the supply chain: Learning from pioneers and RFID research. International Journal of Operations \& Production Management, 39 (6), pp. 829-859.

Volvo Trucks (2017), drive the future conference, available at: https://www.volvotrucks.be/nl-be/news/events/drive-thefuture-conference.html (accessed 20 December 2018).

Wang, Y., Han, J., Beynon, D.P. (2019a), Understanding blockchain technology for future supply chains: a systematic literature review and research agenda. Supply Chain Management, 24 (1), pp. 62-84.

Wang, Y., Singgih, M., Wang, J. and Rit, M. (2019b), Making sense of blockchain technology: How will it transform supply chains. International Journal of Production Economics, 211, pp. 221-236.

Wu, H., Li, Z., King, B., Ben Miled, Z., Wassick, J. and Tazelaar, J. (2017), "A distributed ledger for supply chain physical distribution visibility", Information Journal, 8 (4), pp. 137.

Yin, R.K. (2014), Case Study Research: Design and Methods, Sage Publications, London, England. 
Yli-Huumo, J., Ko, D., Choi, S., Park, S. and Smolander, K. (2016),

Where is current research on blockchain technology?-a systematic review. PLOS ONE, 11 (10).

Abbas Batwa is a teaching assistant at the department of Industrial Engineering at King Abdul-Aziz University, Saudi Arabia. Currently he is on a scholarship as a PhD. Student at Lund University, Sweden. He has a double major MSc. Degrees in logistics and supply chain management from Lund University and in industrial engineering from King Abdul-Aziz University. Abbas has a working background as a logistics manager in Toyota's largest spare parts warehouse in the Middle East region. His research interests are in merging blockchain technology into supply chain management, industry 4.0 applications, and generally utilizing technology innovations for optimizing logistics and supply chain operations.

Andreas Norrman is Professor in Supply chain structure and organization at Lund University, Faculty of Engineering, Sweden. He has a Ph.D. in logistics from Linköping University, Sweden. Andreas has worked as a management consultant at A.T. Kearney with supply chain management and sourcing issues. His research interests include Omni-channel warehousing, Supply chain risk management, Supply chain incentive alignment, Change management and Blockchain. He publishes in leading logistics journal and he received multiple Emerald Highly Commended Awards for his work with IJPD\&LM, both as author and reviewer. Fifteen years ago, he authored the article "Ericsson's proactive supply chain risk management approach after a serious sub-supplier accident" which became one of the most cited articles in SCRM. At Lund University he has been awarded Excellent Teaching Practice. 